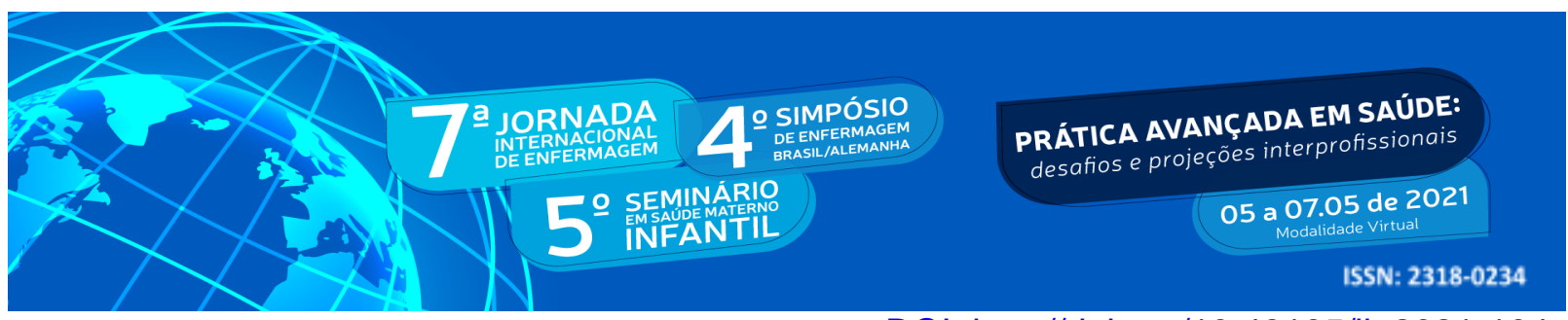

DOI: http://doi.org/10.48195/jie2021-104

\title{
O DESENVOLVIMENTO DE UMA TECNOLOGIA EDUCACIONAL SOBRE SEXUALIDADE: UM RELATO DE EXPERIÊNCIA ${ }^{1}$
}

\section{Isadora Ribeiro Meine ${ }^{2}$; Liliane Tomazi Vestena ${ }^{3}$; Luciana de Andrade Silveira ${ }^{4}$; Josiane Lieberknecht Wathier Abaid ${ }^{5}$.}

\begin{abstract}
RESUMO
A importância das orientações sobre sexualidade na adolescência manifesta-se em função desta contribuir para a formação da identidade e personalidade do sujeito, ou seja, está ligada ao desenvolvimento global. O objetivo deste trabalho foi relatar a construção de uma tecnologia educacional para promover informações sobre a adolescência e sexualidade em meio à da pandemia da COVID-19. Realizou-se um estudo descritivo de natureza qualitativa do tipo relato de experiência, vivenciado pelas autoras. O material foi elaborado na disciplina extensionista de Psicologia nos Processos Educacionais, ministrada no Curso de Graduação em Psicologia. Por meio dela, constatou-se a pluralidade de assuntos e a importância da disseminação de informações acerca da sexualidade durante a adolescência, principalmente, no âmbito escolar. Pretende-se disponibilizar este material para escolas e demais interessados nas páginas do Curso de Psicologia.
\end{abstract}

Palavras-chave: Adolescência; COVID-19; Sexualidade.

\begin{abstract}
The importance of orientations on sexuality in adolescence is manifested in terms of its contribution to the formation of the subject's identity and personality, that is, it is linked to global development. The objective of this work was to report the construction of an educational technology to promote information about adolescence and sexuality in the midst of the COVID-19 pandemic. A qualitative descriptive study of the type of experience report was carried out by the authors. The material was prepared in the extension discipline of Psychology in Educational Processes, given in the Psychology Undergraduate Course. Through it, it was found the plurality of subjects and the importance of the dissemination of information about sexuality during adolescence, mainly in the school environment. It is intended to make this material available to schools and other interested parties on the pages of the Psychology Course.
\end{abstract}

Key Words: Adolescence; COVID-19; Sexuality.

\footnotetext{
${ }^{1}$ Financiamento Próprio

${ }^{2}$ Estudante do Curso de Psicologia. Universidade Franciscana - UFN. E-mail: meineisadora@gmail.com

${ }^{3}$ Estudante do Curso de Psicologia. Universidade Franciscana - UFN. E-mail: liliane.tomazi@ufn.edu.br

${ }^{4}$ Estudante do Curso de Psicologia. Universidade Franciscana - UFN. E-mail: luciana.silveira@ufn.edu.br

${ }^{5}$ Orientadora - Universidade Franciscana - UFN. E-mail: josianelieb@ufn.edu.br
} 


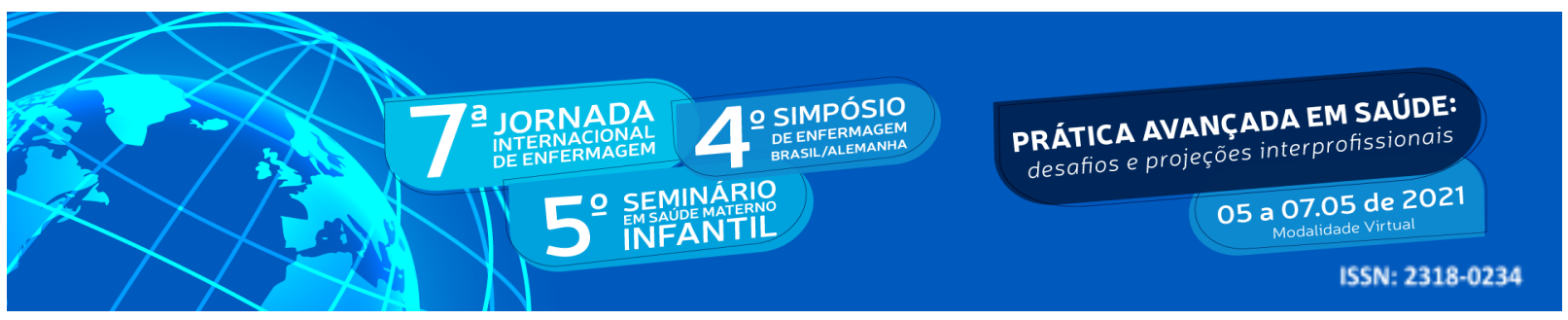

\section{INTRODUÇÃO}

$\mathrm{Na}$ adolescência, ocorrem diversas mudanças físicas, psicológicas, sociais e nas formas de como esses jovens se relacionam consigo, com seus pais e com o mundo (CANO; FERRIANI, 2000). Dentro disso, a sexualidade se encontra como um fator decisivo na estruturação de identidade do sujeito (CANO; FERRIANI, 2000), uma vez que é um aspecto da vida humana e está ligada ao desenvolvimento global do sujeito, constituindo, inclusive, elementos da personalidade (COSTA et al, 2001). Ademais, a sexualidade é marcada por fatores biopsicossociais da adolescência, sendo que pode haver inúmeras descobertas e conflitos neste período. Ela, ainda, é uma construção social e histórica, sendo que ganha contornos e significados em diferentes espaços e tempos (MORAIS; VITALLE, 2012).

Atualmente, a sexualidade tem sido um tema bastante debatido entre pais, educadores e profissionais da saúde, devido a sua importância (CANO; FERRIANI, 2000). Porém, muitas vezes, os meios de comunicação utilizam as questões sobre sexualidade de forma banalizada, tirando a possibilidade de o adolescente fazer uma reflexão sobre este tema tão significativo (COSTA et al, 2001).

Ainda convém lembrar que, durante a pandemia, houve diversos assuntos em pauta sobre cuidados e formas de prevenção ao COVID-19. Contudo, nesse contexto, há uma população de jovens, que pode estar desassistida de conhecimentos acerca da sexualidade na adolescência, que podem ser capazes de evitar complicações, que, em sua maioria, teriam soluções. Dentro desse viés, pode-se citar as infecções sexualmente transmissíveis ou até questões relacionadas à identificação de gênero. Isto é, temáticas fundamentais (FACCHINI; DANILIAUSKAS; PILON, 2013).

\section{OBJETIVO}

Esta atividade de extensão teve como objetivo promover maiores informações sobre a adolescência e sexualidade, juntamente com o contexto da pandemia do COVID-19 por meio da elaboração de uma cartilha informativa. 


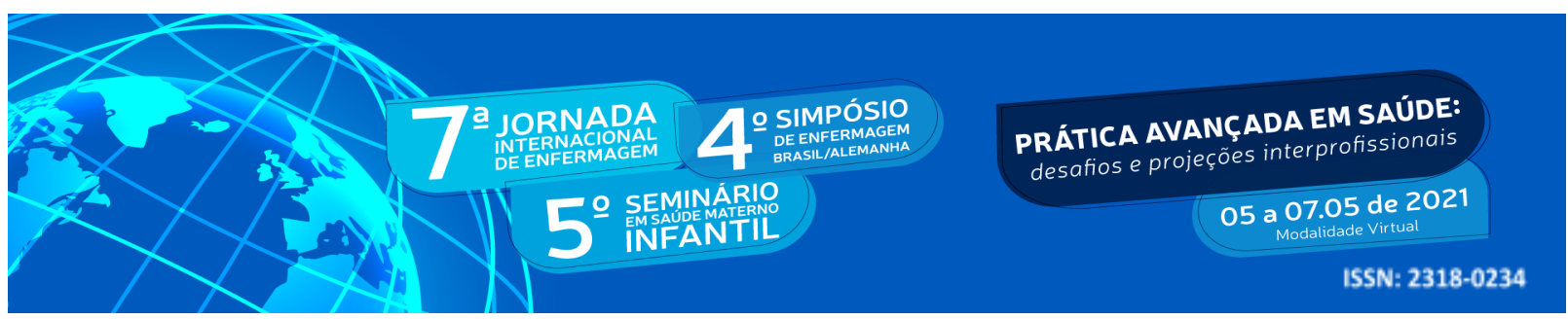

\section{METODOLOGIA}

Estudo descritivo de natureza qualitativa do tipo relato de experiência, vivenciado pelas autoras. O relato de experiência é uma ferramenta da pesquisa descritiva que apresenta uma reflexão sobre uma ação ou um conjunto de ações que abordam uma situação vivenciada no âmbito profissional de interesse da comunidade científica (VYGOTSKY, 1989).

A proposta de concepção e construção de uma tecnologia educacional do tipo cartilha (material didático) ocorreu no período de outubro a dezembro de 2020. Trata-se de um produto decorrente dos conhecimentos adquiridos pelas autoras durante o seu planejamento e em sua elaboração. A referida cartilha está vinculada à disciplina extensionista de Psicologia nos Processos Educacionais, ministrada no Curso de Graduação em Psicologia pela professora Josiane Lieberknecht Wathier Abaid.

Para abordar a temática da sexualidade na adolescência em contexto pandêmico motivado pelo COVID-19, utilizou-se o formato da cartilha. Nela, além de textos (produzidos a partir da leitura de artigos, cartilhas e semelhantes), foram utilizadas imagens (todas disponíveis no site intitulado Freepik), as quais tornaram-na mais atrativa.

Ademais, a cartilha foi integralmente arquitetada na plataforma do "Google Drive", mais especificamente no espaço "Apresentações do Google", como se fosse uma apresentação de slides, apesar das dimensões adotadas nas páginas serem de 21 x 29 centímetros, aproximando-se das dimensões de uma folha A4.

\section{RESULTADOS E DISCUSSÃO}

Antes da elaboração da cartilha (Figuras 1, 2, 3 e 4), decidiu-se que seria realizada alguma atividade de intervenção voltada à sexualidade na adolescência, correlacionando com o contexto atual de pandemia. Assim, à priori, surgiu a ideia da realização de rodas de conversas com adolescentes, que estivessem com cerca de quinze anos de idade, ou seja, primordialmente no final do ensino fundamental e no início do ensino médio. Tais conversas seriam feitas em três encontros virtuais, no Google meet, cada um com cerca de uma hora e meia. Neles, além de proporcionar um ambiente de escuta e de acolhimento, seria abordado o 


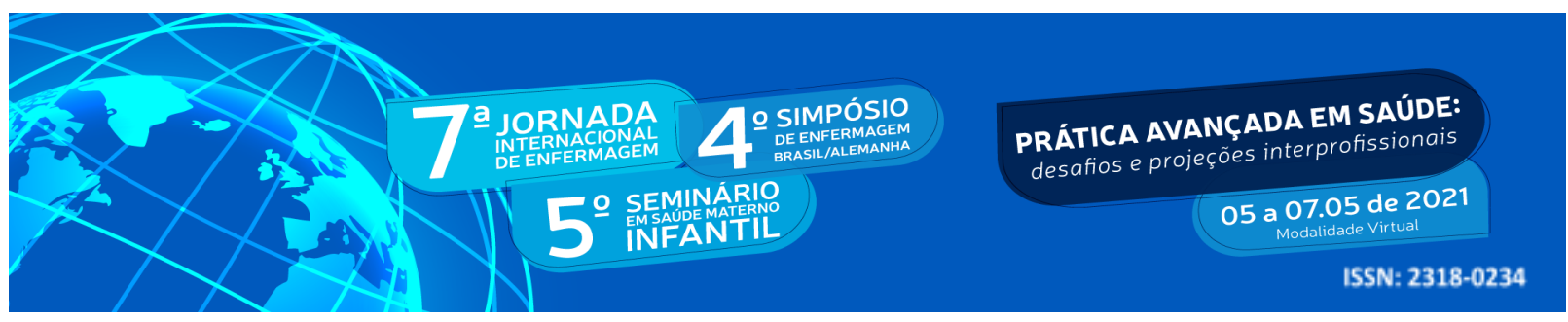

que é sexualidade e suas múltiplas formas de expressão, como se dá a concepção, métodos contraceptivos, infecções sexualmente transmissíveis e o impacto da pandemia e do distanciamento físico no desenvolvimento da sexualidade desses jovens. Como ferramenta auxiliar pensou-se até em elaborar perguntas, em formato de jogo, no site Kahoot.

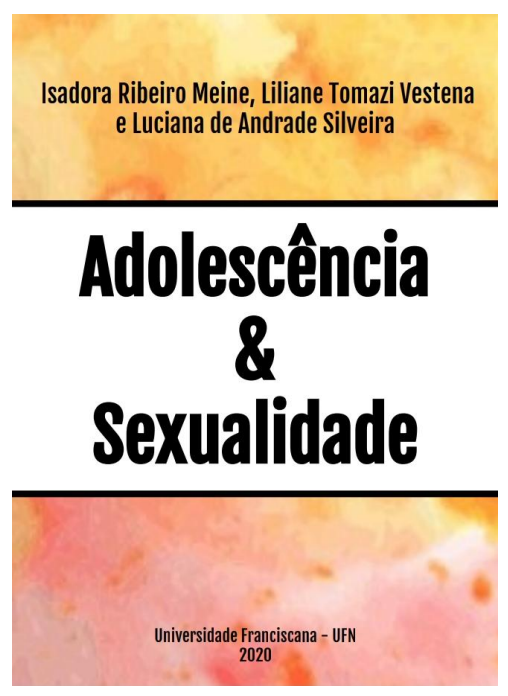

Figura 1: Capa.

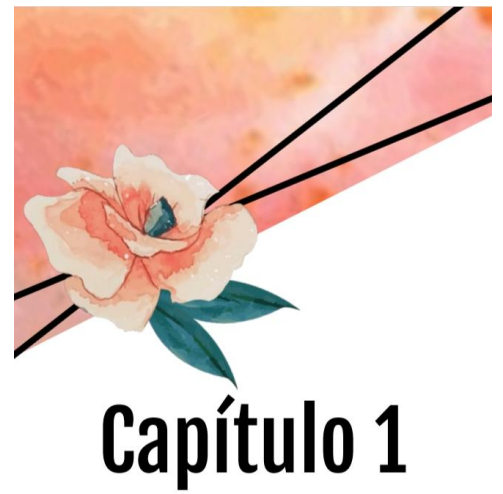

Adolescência e sexualidade

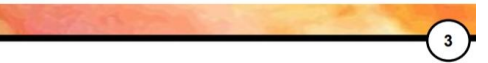

Figura 3: Design da página dos capítulos.

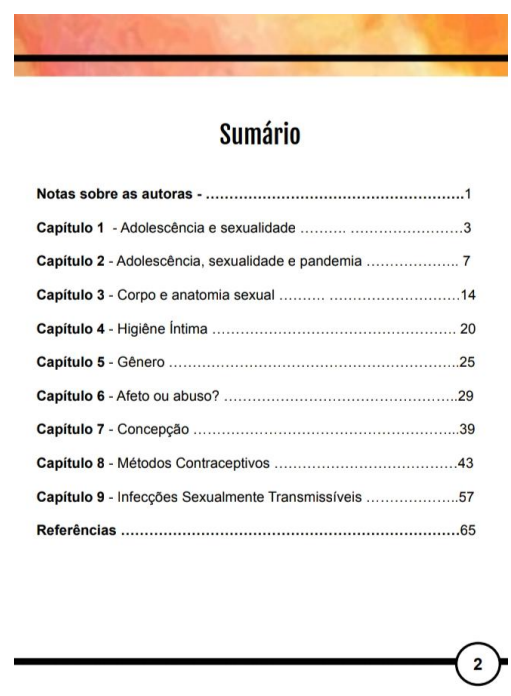

Figura 2: Sumário.

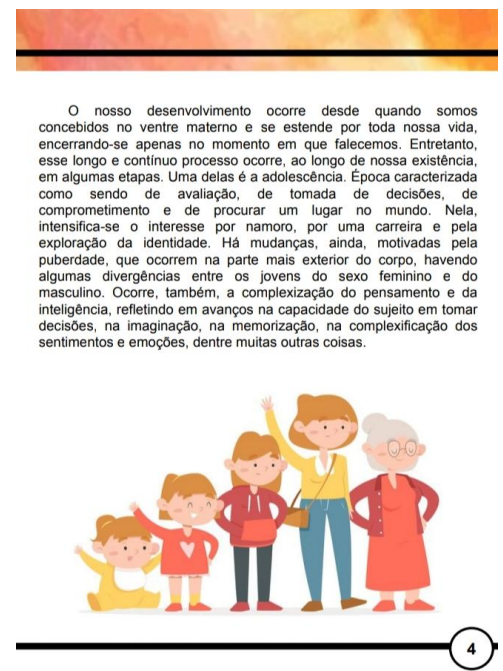

Figura 4: Design de exemplo do corpo do texto.

Foi marcada uma reunião com os professores de uma escola, na qual visava-se a realização da conversa com os adolescentes, em que houve a oportunidade de conhecer a 


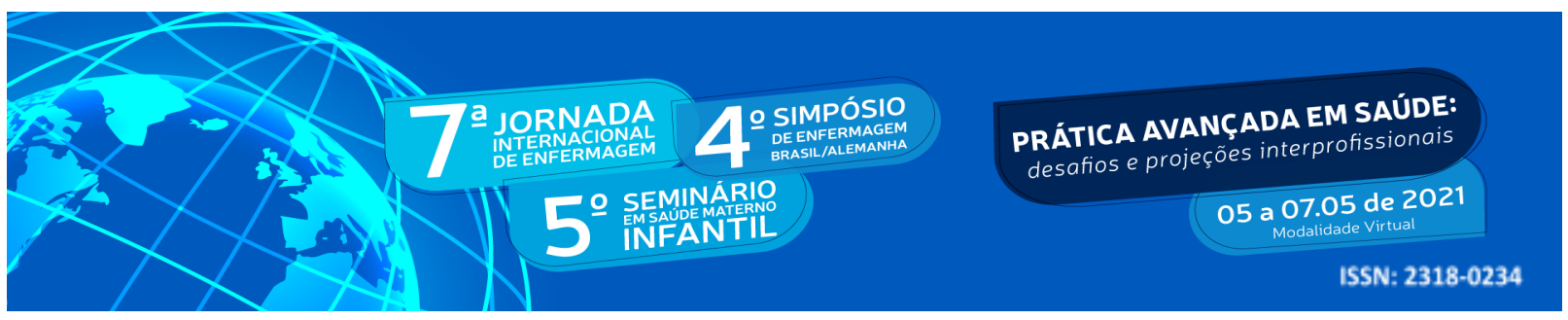

equipe docente e, ainda, apresentou-se os estudantes que lá iriam intervir e suas respectivas propostas. Depois dessa reunião, contudo, alguns aspectos impulsionaram a modificação desse projeto de intervenção. Dentre eles:

- A dificuldade de alguns alunos em acessar meios tecnológicos que permitissem a realização da chamada de vídeo;

- O cansaço promovido pelo uso demasiado de aparelhos eletrônicos durante a pandemia;

- A amplitude da temática e a dificuldade das estudantes de Psicologia em conseguir dar conta de possíveis demandas que fossem além de suas capacidades técnicas e teóricas;

- A pequena disseminação de informações, haja vista que o grupo de alunos seria constituído por cerca de quinze alunos;

- Dificuldades da escola em conseguir dar conta de suas demandas mais urgentes como a adaptação do currículo estudantil ao contexto on-line e pensar em estratégias para remediar as respectivas dificuldades - e, ainda, conseguir organizar um grupo de alunos que estivesse interesse na temática proposta;

Diante disso, a cartilha se mostrou como um meio eficaz para que o nosso objetivo fosse contemplado. Isto pois:

- A cartilha pode ser acessada por diversos dispositivos tecnológicos, utilizando uma quantidade de internet inferior ao que seria necessário para a realização da chamada de vídeo;

- A cartilha poderia ser lida e relida à qualquer momento do dia, podendo, ainda, sua leitura ser realizada aos poucos e junto às atividades de algumas disciplinas das escolas;

- Todos os assuntos abordados na cartilha foram cuidadosamente estudados e revisados, garantindo uma maior qualidade nos conteúdos nela disponíveis. Além disso, pode-se mesclar os textos com imagens, tornando-a mais didática;

- Por ser de fácil acesso, bastando a realização do download da cartilha, ela poderá ser não apenas difundida no âmbito da escola visada, mas poderá ir além de seus limites, atingindo um público muito mais amplo; 


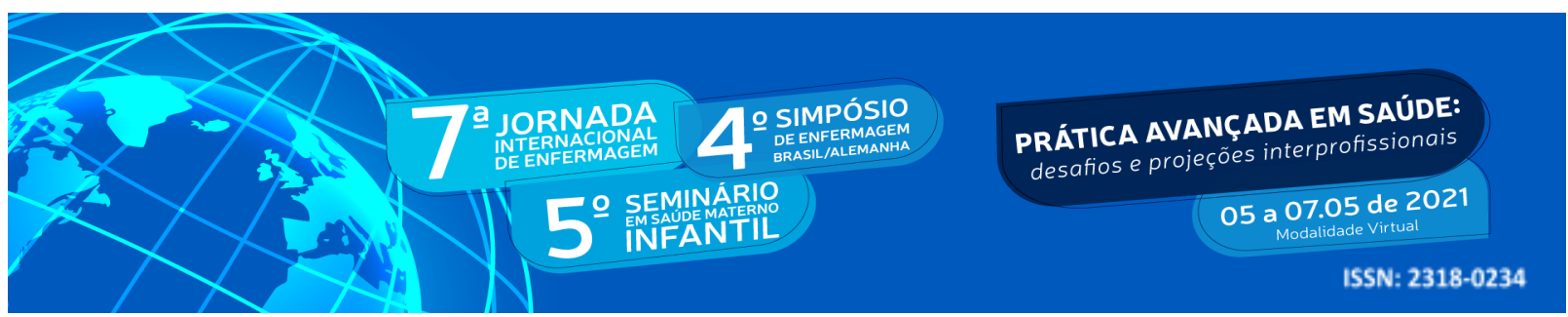

- Com a facilidade do compartilhamento da cartilha, este material não acarretará em maiores dificuldades para a escola, haja vista que o período de pandemia tem trazido demandas desafiadoras às escolas.

Feita a opção pela cartilha, começou-se o levantamento de possíveis assuntos que seriam desenvolvidos e de como eles seriam organizados. Como resultado, tem-se o que foi exposto na Tabela 1, disponível abaixo:

Tabela 1: Síntese dos conteúdos abordados em cada capítulo da cartilha "Adolescer \& sexualidade"

\begin{tabular}{|c|c|c|}
\hline Capítulos & Título dos Capítulos & Conteúdo geral abordado \\
\hline- & Nota sobre as autoras & $\begin{array}{l}\text { Breve contextualização das } \\
\text { autoras e da produção da } \\
\text { cartilha. }\end{array}$ \\
\hline 1 & Adolescência e sexualidade & $\begin{array}{c}\text { O adolescer e suas implicações } \\
\text { físicas, } \\
\text { sociais e afetivas; A } \\
\text { complexidade do presente no } \\
\text { adolescer; Caracterização da } \\
\text { adolescência de acordo com o } \\
\text { ECA, OMS e ONU; a } \\
\text { importância do enfoque na } \\
\text { saúde global dos adolescentes. }\end{array}$ \\
\hline 2 & $\begin{array}{c}\text { Adolescência, sexualidade e } \\
\text { pandemia }\end{array}$ & $\begin{array}{l}\text { Os impactos da pandemia e do } \\
\text { isolamento na saúde mental dos } \\
\text { adolescentes; os impactos } \\
\text { acadêmicos, sociais, } \\
\text { econômicos e psicológicos; o } \\
\text { estabelecimento de rotinas; a } \\
\text { expansão do uso de tecnologias. }\end{array}$ \\
\hline 3 & Corpo e anatomia sexual & $\begin{array}{l}\text { A importância da correlação } \\
\text { entre informações difundidas e } \\
\text { as relações subjetivas; } \\
\text { Autoconhecimento; Mudanças } \\
\text { corporais; Anatomia sexual } \\
\text { feminina e masculina. }\end{array}$ \\
\hline 4 & Higiêne Íntima & $\begin{array}{l}\text { Dicas de como fazer a } \\
\text { higienização íntima }\end{array}$ \\
\hline 5 & Gênero & $\begin{array}{l}\text { Gênero; Identidade de gênero; } \\
\text { orientação sexual; sexo } \\
\text { biológico; expressão de gênero }\end{array}$ \\
\hline
\end{tabular}




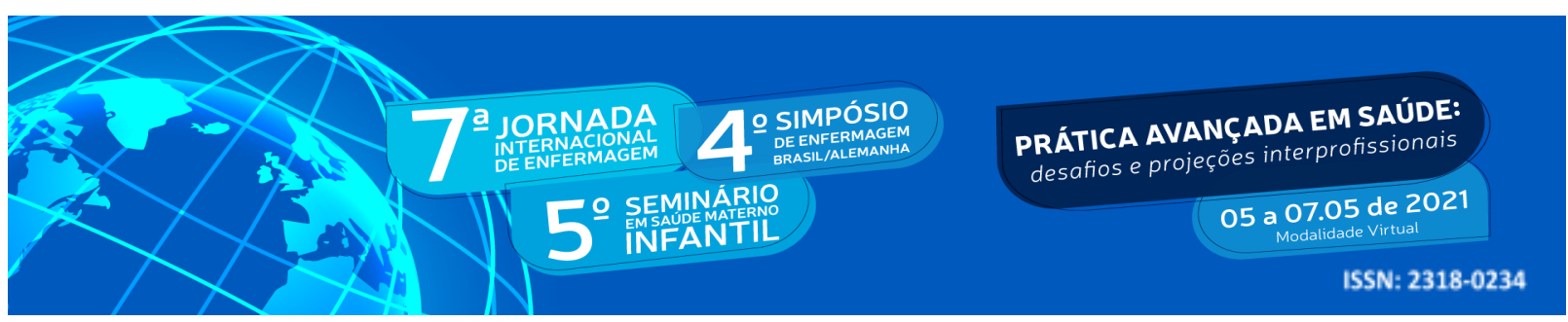

6

7

8

9
Afeto ou abuso?

Concepção

Métodos Contraceptivos

Infecções Sexualmente

Transmissíveis

O que é violência e algumas das formas mais recorrentes (Maus-tratos e abuso, Negligência e Abandono, Negligência física, Negligência emocional, Negligência educacional, Sevícias ou Abuso físico, Abuso sexual e Abuso psicológico); O que fazer diante do contexto de violência; algumas legislações a respeito dos direitos da criança e do adolescente.

Como ocorre a concepção; Sintomas da gravidez.

O que são métodos contraceptivos e qual escolher;

Pílula Anticoncepcional; Injeções Anticoncepcionais; Preservativo/Camisinha externa; Preservativo/Camisinha interna; Diafragma; Espermicida; Muco cervical; Tabela; Dispositivo Intra-uterino - DIU; Coito Interrompido/ gozar fora; Pílula anticoncepcional de emergência/ Pílula do dia seguinte; Vasectomia; Ligadura de Trompas;

O que são DST's/ IST's?; Sífilis; Herpes Genital;

Gonorréia; Cancro-mole;

Tricomoníase; Hepatite B; Papilomavirose Humana/ Condiloma/ HPV; AIDS (Síndrome da Imunodeficiência Adquirida); Como saber se você está com alguma ISTs?; Qual a forma de tratamento?.

Referências

Bibliografia utilizada

Neste sentido, apesar do intenso desenvolvimento sociocultural ocorrido nos últimos séculos, informações relacionadas aos aspectos biopsicossocial e sexual tão indispensáveis 


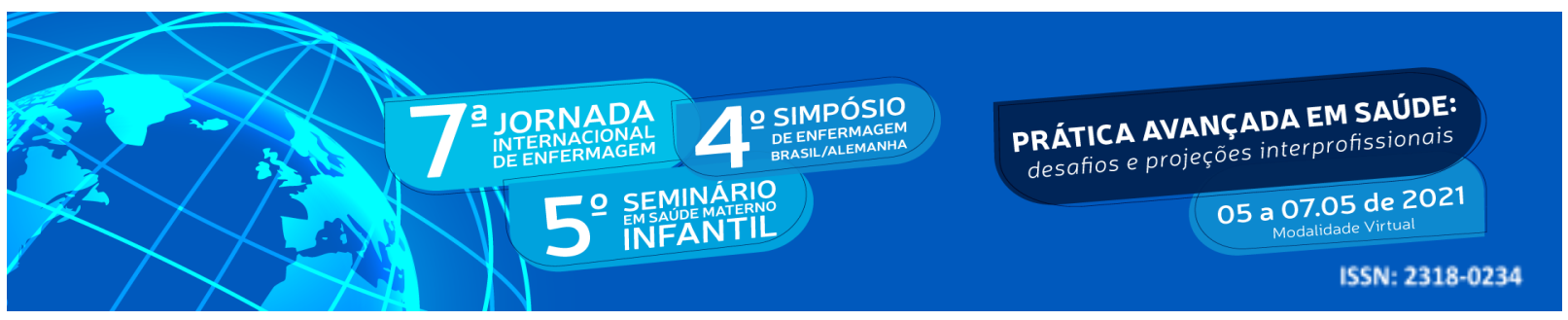

para a construção da identidade do sujeito não tem chegado de forma explícita, ampla e adequada a grande parte dos adolescentes. Além disso, quando recebe informações são por parte da família e escola, mas de forma restrita, geralmente, ao uso de preservativos para evitar DSTs. Assim, percebe-se que uma grande gama de assuntos relacionados a sexualidade e ao desenvolvimento do indivíduo ficam restritos tais como: funcionamento do corpo, maturação sexual, violência sexual dificultando a adoção de hábitos saudáveis por parte dos adolescentes (GOMES, et al, 2002).

Neste panorama, durante a elaboração deste material, esbarramos com algumas dificuldades. A primeira delas foi em relação a adoção de uma escrita de fácil compreensão. Depois, surgiram dificuldades acerca dos conteúdos que seriam abordados, já que, apesar de termos uma temática a focalizar em cada capítulo, foi complexo delimitar o que de fato seria escrito. Para tanto, uma professora que ministra a disciplina de biologia na escola para a qual foi direcionada o material, auxiliou-nos nessa delimitação. Além disso, tivemos dificuldades em encontrar imagens que fossem não apenas gratuitas, mas que tivessem certa qualidade e que, ao mesmo tempo, atingissem nossos objetivos.

A elaboração da cartilha foi realizada com muita minúcia e cuidado, o que exigiu significativa demanda de tempo e energia. Contudo, por mais que tenha sido uma empreitada de complexa elaboração, as autoras sentem-se satisfeitas, não apenas do resultado de sua produção, mas, também, dos conhecimentos aprendidos no em todo o percurso da atividade extensionista.

\section{CONCLUSÃO}

Dado o exposto, se consegue analisar o quanto se é primordial debater e obter um material qualificado quando o assunto é sexualidade na adolescência, posto que, nesta fase da vida há muitas ansiedades e frustrações, que quando esclarecidas podem vir a ser amenizadas ou até mesmo sanadas. Logo, o foco principal é de que jovens e alunos possam usufruir da cartilha educativa a modo de corrigir eventuais dúvidas que teriam, as quais na maioria das vezes infelizmente não são pautadas em sala de aula. 


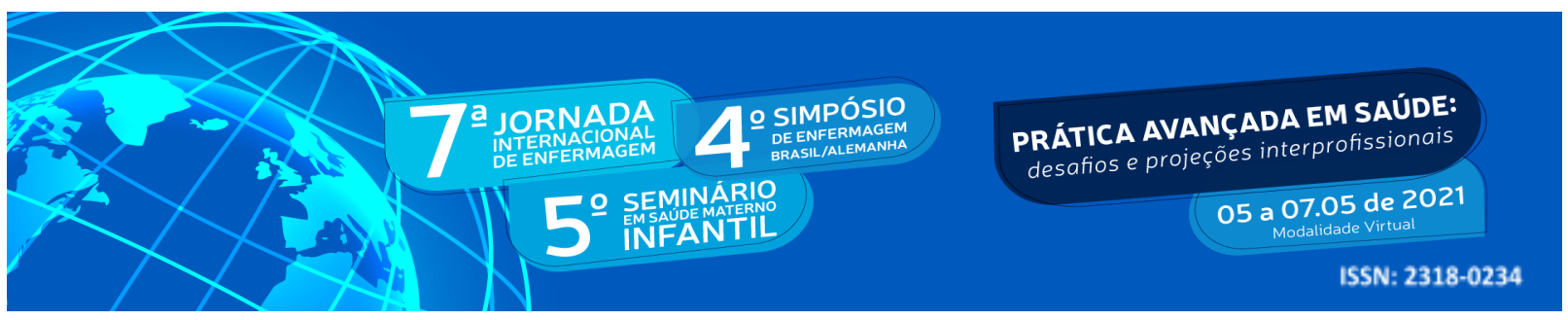

Desse modo, a ideia norteadora deste relato de experiência foi que ele possa contribuir para discussões e reflexões sobre a importância de trabalhar o tema da sexualidade com os adolescentes dentro da família e também da escola, desmistificando tabus e proporcionando maiores informações sobre os cuidados e também sobre a prevenção de DSTs.

Neste sentido, fica a sugestão de que cada vez mais sejam abordados esses temas relacionados à sexualidade e adolescência como uma forma de promoção de saúde, para que estes sintam-se amparados em suas dúvidas e que essas informações possam contribuir para a autonomia dos mesmos, diante de um período tão atípico em que estamos vivendo.

\section{REFERÊNCIAS}

CANO, M. A. T.; FERRIANI, M. das G. C. Sexualidade na adolescência: um estudo bibliográfico. Revista Latino Americana de Enfermagem, Ribeirão Preto, v. 8, n. 2, p. 18-24, abril 2000. Disponível em: https://www.scielo.br/pdf/rlae/v8n2/12413. Acesso em: 26 Nov. 2020.

COSTA, M. C. O. et al. Sexualidade na adolescência: desenvolvimento, vivência e propostas de intervenção. Jornal de Pediatria, v. 77, Supl.2, 2001. Disponível em: http://www.jped.com.br/conteudo/01-77-s217/port.pdf. Acesso em: 26 Nov. 2020.

FACCHINI, R.; DANILIAUSKAS, M.; PILON, A. C. Políticas sexuais e produção de conhecimento no Brasil: situando estudos sobre sexualidade e suas conexões. Revista de Ciências Sociais, Fortaleza, v. 44, n. 1, p. 161-193, 2013. Disponível em: http://repositorio.ufc.br/handle/riufc/9115. Acesso em: 27 Nov. 2020.

GOMES, W. de A. et al. Nível de informação sobre adolescência, puberdade e sexualidade entre adolescentes. Jornal de Pediatria, v. 78, n. 4, 2002. Disponível em:https://www.scielo.br/pdf/jped/v78n4/v78n4a09.pdf. Acesso em: 17 Dez. 2020.

MORAIS, S. P. de; VITALLE, M. S. de S. Direitos sexuais e reprodutivos na adolescência. Revista Associação Medicina Brasileira, v. 58, n. 1, p. 48-52, 2012. Disponível em: scielo.br/pdf/ramb/v58n1/v58n1a14.pdf. Acesso em: 26 Nov. 2020. 


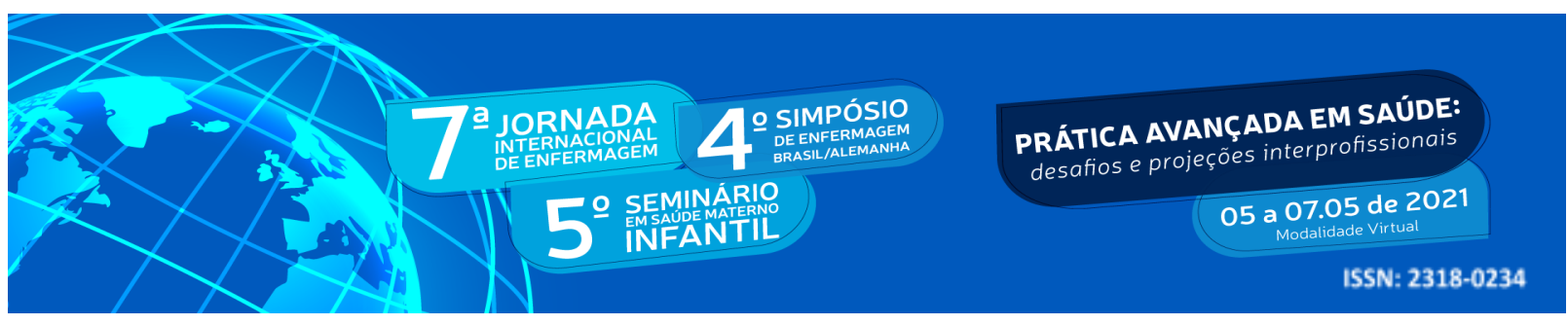

VYGOTSKY, L.S. A formação social da mente. (trad. Luis Silveira Menna Barreto, Solange Castro Afeche, José Cipolla Neto, ed. orig. 1960). São Paulo: Martins Fontes, 1989. 